\title{
The Effects of Either Height of Bellows Ends on the Stress Distribution according to Rotation Angles
}

\author{
Jin-Bong $\mathrm{KIM}^{1 \text {, a }}$ \\ ${ }^{1}$ Department of Aeronautical and Mechanical Eng., Hanseo University, 236-49, Gomsum-ro, Nammyun, Taean, Chungnam, Korea
}

\begin{abstract}
As analysis research, the effect of either height of bellows ends on the stress distribution has been proposed in the study. Rotation angle only is considered as a boundary condition. FEM solution for a u-shaped flexible tube under the action of angle of rotation is obtained. The design factor, convolution height of bellows ends, is considered for the simulation. The analysis is performed using the finite element analysis program. The maximum von-Mises stress and its reduction rate according to the height of bellows ends is compared respectively.
\end{abstract}

\section{Introduction}

Numerous papers have dealt with various aspects of bellows; Broman et al.[1] have determined dynamic characteristics of bellows by manipulating certain parameters of the beam finite elements, Jakubauskas and Werner[2] have considered the transverse vibrations of fluid-filled double-bellows expansion joints. Jha et al.[3] have investigated the stress corrosion cracking of stainless steel bellows of satellite launch vehicle propellant tank assembly. Zhu et al. [4] have investigated the effect of environmental medium on fatigue life for $\mathrm{u}-$ shaped bellows expansion joints. In addition, Becht [5] has investigated the fatigue behavior of expansion joint bellows.

Usage of the bellows has been increased due to its inherent flexibility and excellent anti vibration properties. It has been used for a long time in many engineering applications, therefore, numerous papers dealt with bellows have found in the literatures. Many design formulae of the bellows can be found in ASME code [6]. And the most comprehensive and widely accepted text on bellows design is the Standards of Expansion Joint Manufactures Association, EJMA [7]. A comparison of the ASME code and the EJMA standards is given by Hanna [8], concluding that the two conform quite well in most aspects. In addition, the EJMA standards were compared with finite element and experimental analyses in some papers. But simplified equations are contained in EJMA, so it includes excessive safety factor and design errors. In order to compensate errors, service conditions in the design are considered in some studies [9].

Flexible tubes consist of a thin walled shell of revolution with a corrugated meridian in order to provide the flexibility needed to absorb mechanical movements. As the geometry of flexible tube is complex, it is difficult to analyze the mechanical behavior of flexible tubes. In some cases, the axi-symmetrical deformation problems of flexible tubes have been studied [10], and these problems were investigated by the finite difference method [11].

Proper dimensioning requires deep understanding of the characteristics of the flexible tubes and their interaction with the rest of the exhaust system. Off the shelf products seldom fit a specific application, which was experienced when flexible tubes were introduced into exhaust systems. Failure as shown in Figure 1,2 took place after rather short operation times and substitution of stronger and much more expensive material did not solve the problem [12]. In order to prevent these failures, it is necessary to design an optimum shape reducing maximum stress. The design factors, mountain height, length, thickness, and the number of convolutions should be considered and the proper values should be chosen for optimum design. As maximum stress is initiated at both ends of bellows, it is necessary to analysis the effects of height of bellows ends on the maximum stress. The aim of this work is to find a relationship between the height of bellows ends and the rotation angle upon maximum von_Mises stress and stress reduction rate.

\section{Analysis Model}

To obtain the flexible tube profile, it was modeled with the finite element code. The flexible tube was meshed with 8 node shell elements and elastic - plastic non-linear analysis was performed.

Material properties and dimensions used in the analysis are described in Table 1 . The yield stress for the model used in the study is $353 \mathrm{MPa}$ and ANSYS was used as FE-solver for stress analysis. Analysis model is shown in Fig. 1. Fig. 1 displays the geometry profile for the analysis model. The height of convolution from both end

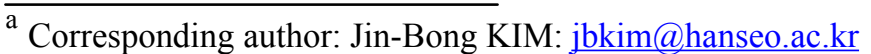


caps of the flexible tube varies as shown in Fig. 1. The height of $1 \mathrm{st}$ convolution varies from $4 \mathrm{~mm}$ to $10 \mathrm{~mm}$. The pitch of convolution is $6.8 \mathrm{~mm}$. The mesh consists of 112,800 elements. One side is fixed and lateral displacement of $0 \mathrm{~mm}$ and angle of rotation from 0.01 to 0.21 degrees was applied on the other side for boundary condition.

Table 1, Material properties and geometric dimensions

\begin{tabular}{c|c|c|c|c|c}
\hline $\begin{array}{c}\text { Tangent Modulus } \\
{[\mathrm{GPa}]}\end{array}$ & $\begin{array}{c}\text { Young's Modulus } \\
{[\mathrm{GPa}]}\end{array}$ & $\begin{array}{c}\text { Inner Diameter of } \\
\text { Tube[mm] }\end{array}$ & $\begin{array}{c}\text { Thickness } \\
{[\mathrm{mm}]}\end{array}$ & $\begin{array}{c}\text { Quantities of } \\
\text { Flexible tube } \\
{[\mathrm{ea}]}\end{array}$ & Type of Element \\
\hline 1.880 & 188 & 64.32 & 0.315 & 23 & 8 -node Shell \\
\hline
\end{tabular}

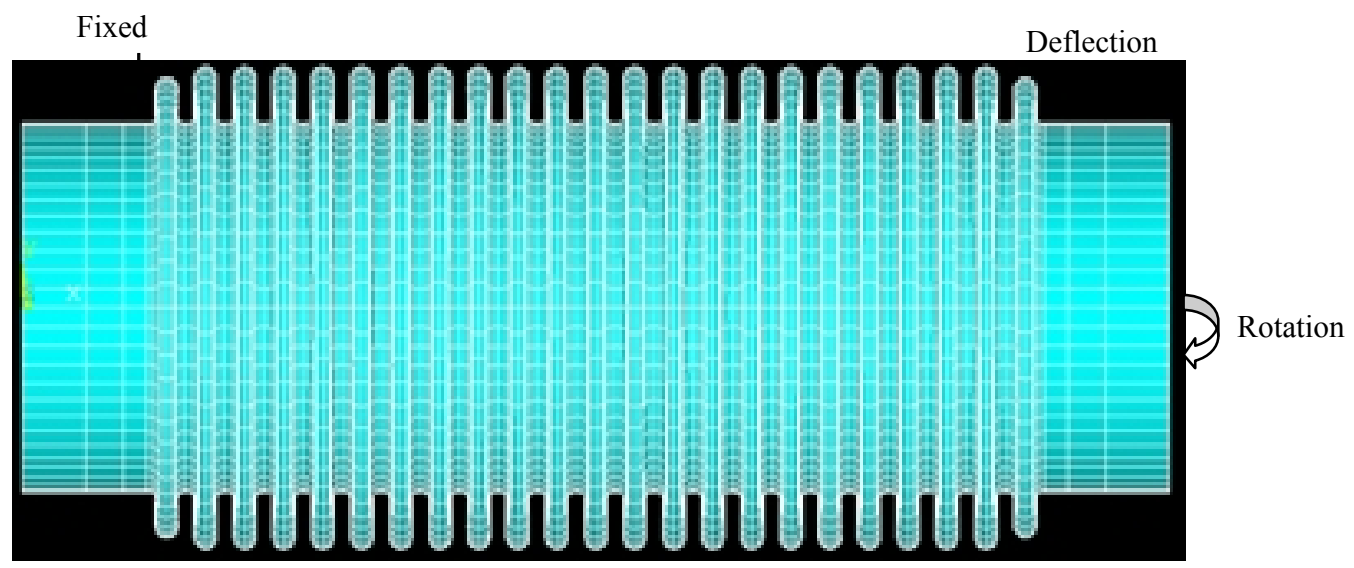

Figure 1. Analysis Model and Boundary Condition

\section{Results and discussions}

Fig. 2 represents the von-Mises stress distribution in the case of $0 \mathrm{~mm}$ deflection with 0.01 degree rotation at the end. Maximum von-Mises stress increases from 54MPa to $71 \mathrm{MPa}$ as the height of either ends varies from $4 \mathrm{~mm}$ to $10 \mathrm{~mm}$. On the contrary to this, maximum von-Mises stress decreases from $389 \mathrm{MPa}$ to $361 \mathrm{MPa}$ as the height of either ends varies from $4 \mathrm{~mm}$ to $10 \mathrm{~mm}$ as shown in Fig. 3 .

Fig. 4 (a) represents maximum von-Mises stress versus height of either bellows ends at $0 \mathrm{~mm}$ lateral deflection with angle of rotation at the end. Each symbol represents for results at the boundary condition of rotation angle. Maximum stress increases as height of either ends increases in the elastic range of rotation 0.01 degree to 0.07 degree. Maximum von-Mises stress is almost uniform at 0.09 degree rotation angle and steadily decline in the plastic range that rotation angle is greater than 0.09 degree as the height of bellows ends increase.

Fig. 4 (b) represents maximum von-Mises stress versus rotation angle for each height of bellows ends. Maximum von-Mises stress becomes larger as the height of either bellows ends increases within 0.09 degree rotation angle (elastic range). On the contrary to this, maximum von-Mises stress becomes smaller as the height of either ends increases and the rotation angle is more than 0.09 degree (plastic range).

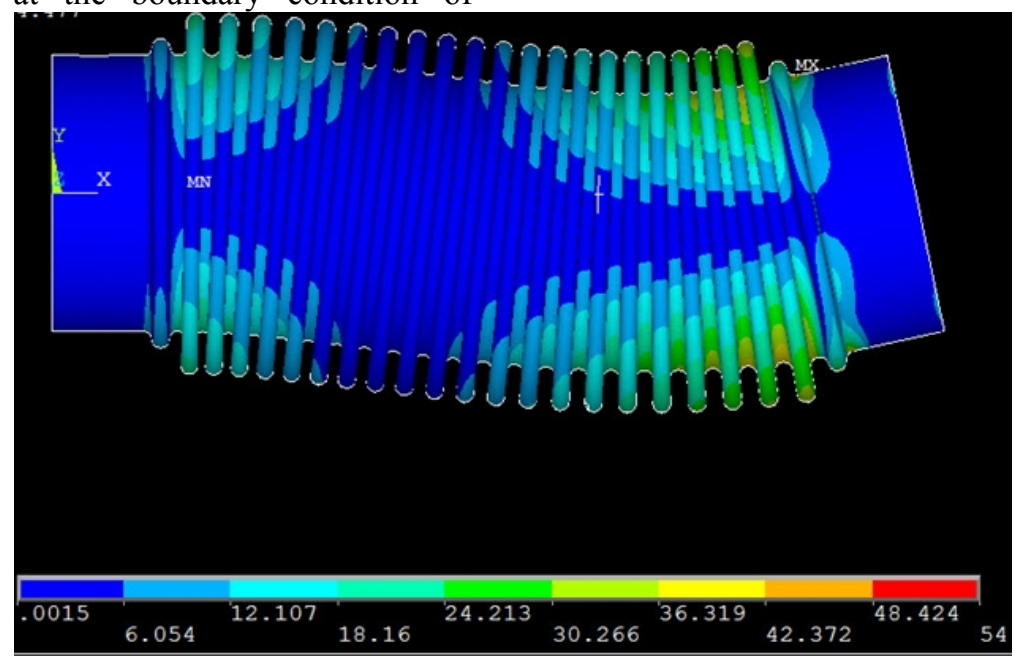

(a) $4 \mathrm{~mm}$ height $(54 \mathrm{MPa})$ 


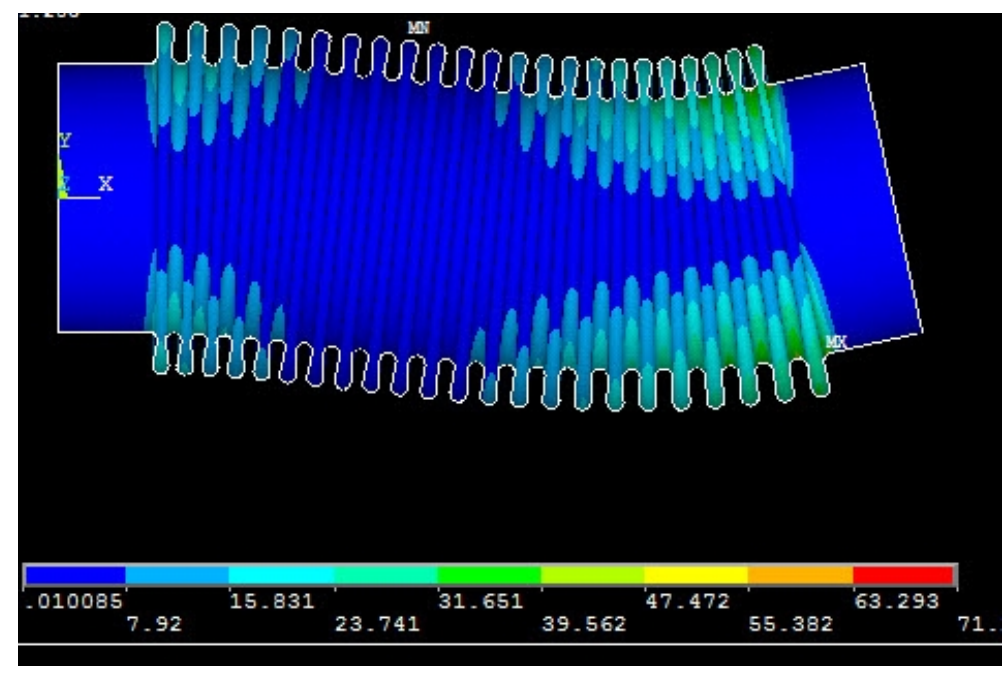

(b) $10 \mathrm{~mm}$ height (71MPa)

Figure 2. von-Mises stress with $0 \mathrm{~mm}$ deflection and 0.01 degree rotation

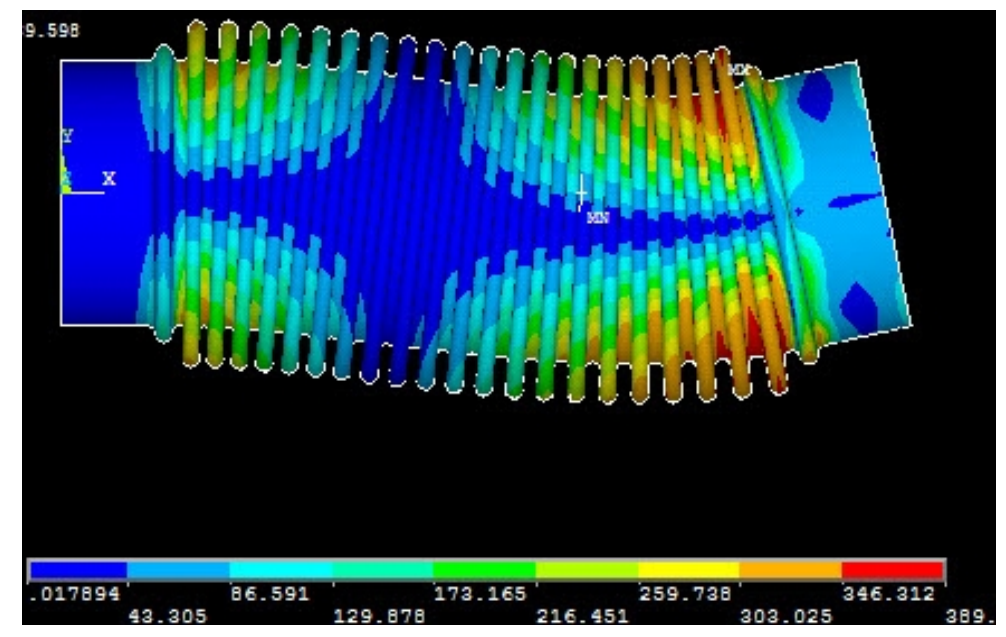

(a) $4 \mathrm{~mm}$ height $(389 \mathrm{MPa})$

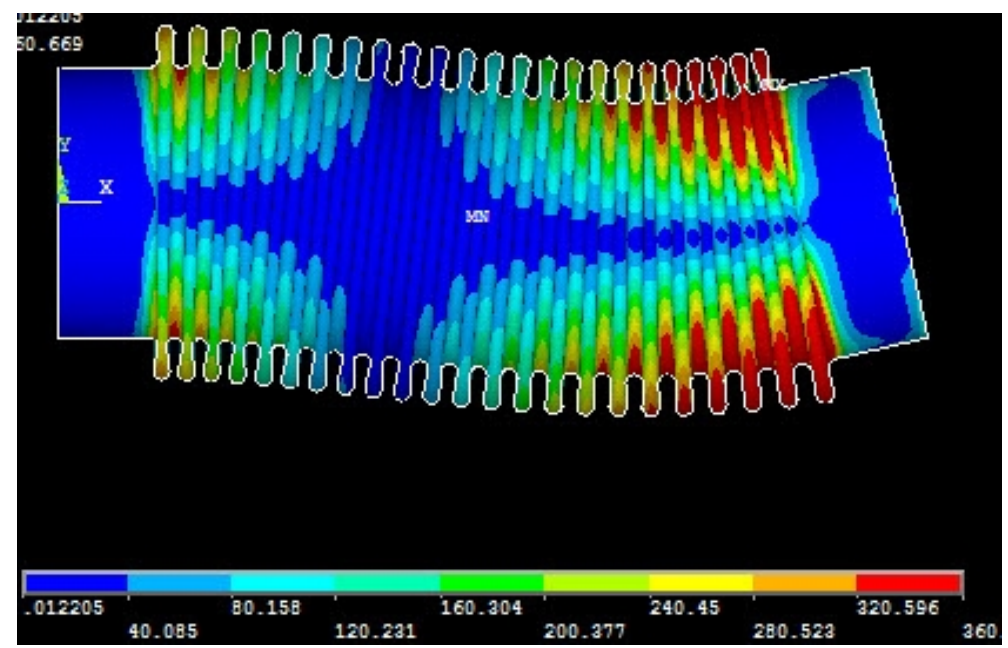

(b) $10 \mathrm{~mm}$ height $(361 \mathrm{MPa})$

Figure 3, von-Mises stress with $0 \mathrm{~mm}$ deflection and 0.17 degree rotation 


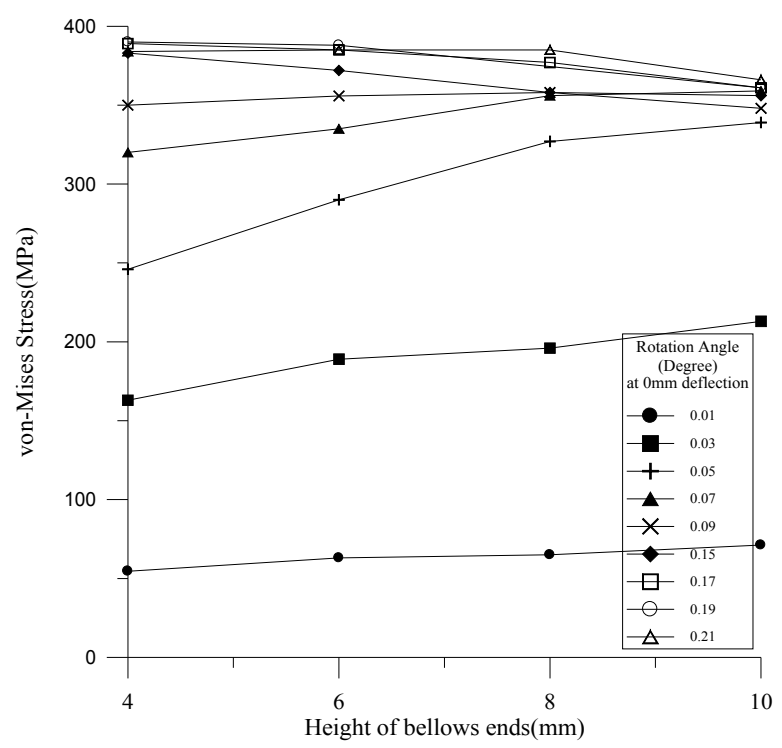

(a) $\sigma$ Vmax-Height of bellows ends

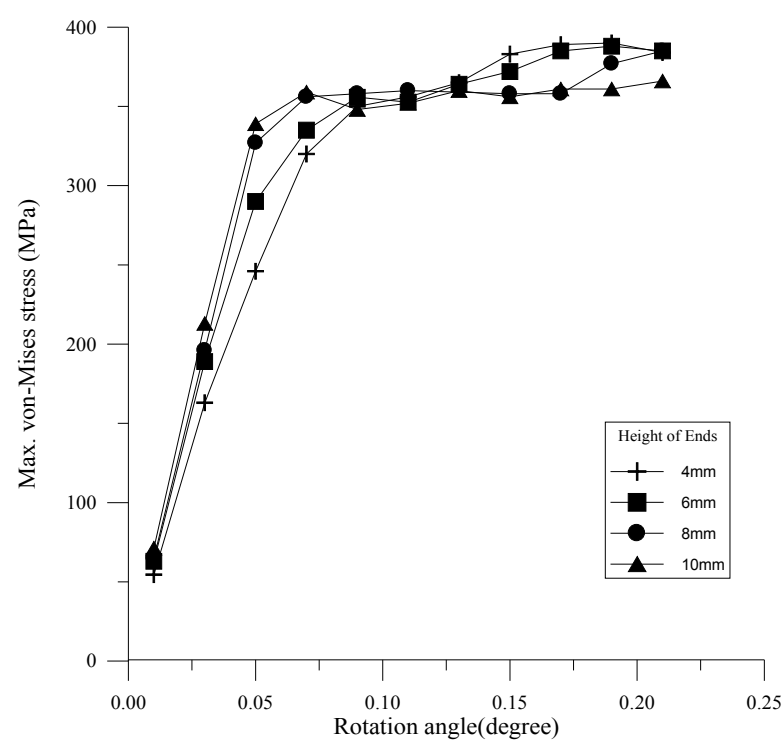

(b) $\sigma$ Vmax-Rotation angle

Figure 4, Max. von-Mises stress at $0 \mathrm{~mm}$ deflection

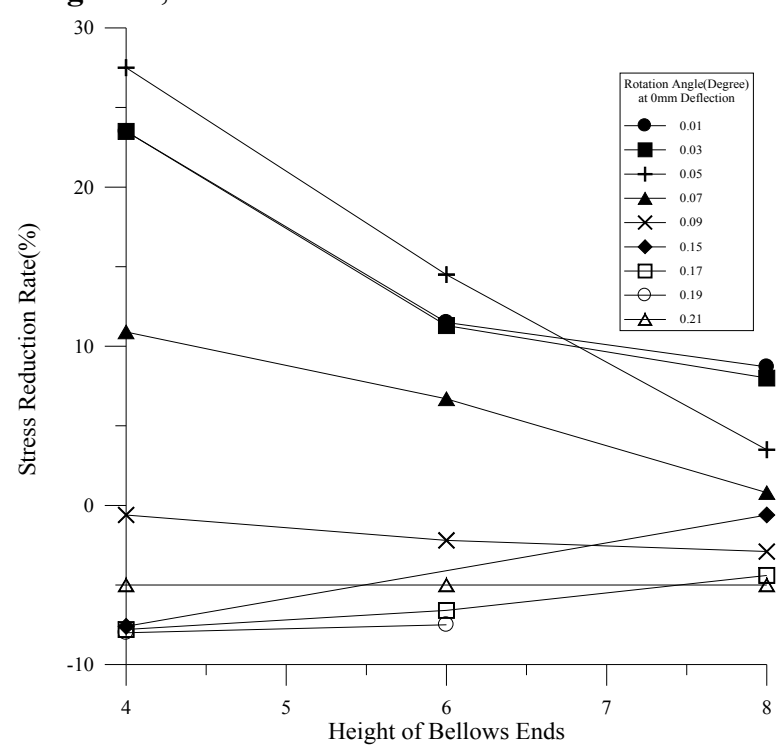

Figure 5, Stress Reduction rate at $0 \mathrm{~mm}$ deflection

Fig. 5 represents stress reduction rate versus the height of either bellows ends at $0 \mathrm{~mm}$ lateral deflection with angle of rotation at the end. The height of bellows except both ends is $10 \mathrm{~mm}$ and maximum von-Mises stress is obtained with variation of either height of bellows ends. Maximum von-Mises stress obtained at either end height of $4 \mathrm{~mm}, 6 \mathrm{~mm}$ and $8 \mathrm{~mm}$ is compared with maximum vonMises stress obtained at a height of $10 \mathrm{~mm}$ ends. Stress reduction rate is obtained as follows.

S.R.R.(Stress Reduction Rate $)=\left(\sigma_{\mathrm{Vmax}}\right.$ at $10 \mathrm{~mm}-$

$\left.\sigma_{\text {Vmax at } 4,6,8 \mathrm{~mm}}\right) / \sigma_{\mathrm{Vmax}}$ at $10 \mathrm{~mm}$

$\sigma_{V \max }:$ Maximum von-Mises stress (2)

SRR is maximum at the rotation angle 0.05 degree. If the rotation angle is less than 0.09 degree (elastic range), SSR decreases steadily and the maximum von-Mises stress increases as the height of both ends increases. In case of 0.09 degree rotation, SSR becomes nearly 0 and maximum von-Mises does not change as the height of either ends varies. If the rotation angle is more than 0.09 degree (plastic range), SSR increases steadily as the height of either ends increases.

\section{Conclusions}

The results for the effects of either height of bellows ends on the stress distribution at the changes of rotation angle can be summarized as follows.

(1) The maximum von-Mises stress is affected not only by the angle of rotation, but also the height of bellows ends.

(2) Stress reduction rate according to the height of bellows ends varies from $-10 \%$ to $30 \%$ for the model. SSR decreases steadily and the maximum von-Mises stress increases as the height of both ends increases in the 
elastic range. On the contrary, SSR increases steadily as the height of either ends increases in the plastic range

\section{References}

Here are some examples:

1. G.I. Broman, A.P. Jonsson and M.P. Hermann: Int. J. Press. Vessels Pip. Vol. 77 (2000).

2. V. Jakubauskas and D.S. Werner: J. Fluids Struct. Vol. 13 (1999).

3. K. Abhay, V. Diwakar and K. Sreekumar: J. Eng. Fail. Anal. Vol. 10 (2003).

4. Y.Z. Zhu, H.F. Wang and Z.F. Sang: Int. J. Fatigue Vol. 28 (2005).

5. Becht IV: Int. J. Pressure Vessels Piping Vol. 77 (2000).

6. ASME Boiler and Pressure Vessel Code-Section VIII, Division 1, Appendix 26 -Pressure Vessel and Heat Exchanger Joints, ASME, NY(2000).

7. Standards of Expansion Joint Manufacturers Association, ninth edition, EJMA, NY (2009).

8. J.W.Hanna: The 1989 ASME Pressure Vessels and Piping Conference (1989).

9. M.S. Han, J.H. Ahn and C.H. Yang: Trans. of KSAE Vol. 21, No. 2 (2013).

10. W.M. Chien: Applied Mathematics and Mechanics Vol. 4, No. 5(1983).

11. M. Hamada, K. Nakagawa and K. Miyata K: Bulletin of JSME Vol. 14(71) (1971).

12. K.Althini and P. Folkesson: Personal communication and unpublished internal reports, AP Automotive Systems, Inc., Torsas, Sweden, (1999). 